\title{
Static respiratory compliance in the newborn. III: Early changes after exogenous surfactant treatment
}

Ben J Stenson, Rebecca M Glover, Gareth J Parry, Rosalie A Wilkie, Ian A Laing, William O Tarnow-Mordi

\begin{abstract}
Static respiratory system compliance (Crs) was measured by a single breath passive expiratory flow technique in 73 newborn infants treated with exogenous surfactant. The first 39 received Curosurf, a natural porcine surfactant. The other 34 received Exosurf Neonatal, a synthetic surfactant. All had a diagnosis of respiratory distress syndrome with an arterial/alveolar oxygen ratio $<0 \cdot 22$. Static Crs and arterial blood gases were measured shortly before, and at three and 12 hours after the first dose of surfactant. In 32 infants treated with Curosurf with initial static Crs $<1.8 \mathrm{ml} / \mathrm{cm} \mathrm{H}_{2} \mathrm{O} / \mathrm{m}$ body length, which is consistent with surfactant deficiency, static Crs improved by $18 \%$ at three hours and by $39 \%$ at 12 hours along with a median reduction in fractional inspired oxygen $\left(\mathrm{FIO}_{2}\right)$ at three hours by 0.32. In 26 infants treated with Exosurf with initial Crs $<1.8 \mathrm{ml} / \mathrm{cm} \mathrm{H}_{2} \mathrm{O} / \mathrm{m}$, Crs did not improve three and 12 hours after treatment and oxygenation improved less than after Curosurf, with a median reduction in $\mathrm{FiO}_{2}$ at three hours of 0.11. Fifteen of the $73(21 \%)$ infants had initial static Crs of $\geqslant 1.8 \mathrm{ml} / \mathrm{cm} \mathrm{H} \mathrm{H} / \mathrm{m}$, not consistent with surfactant deficiency. Thirteen of these 15 infants showed a fall in static Crs after surfactant treatment, raising the question whether exogenous surfactant did them more harm than good. Initial static Crs and surfactant type both appear to determine the early response to the first dose of surfactant. Only a considerably larger, randomised study can show which surfactant is more effective in reducing adverse clinical outcome.

(Arch Dis Child 1994; 70: F19-F24)
\end{abstract}

The early clinical response to exogenous surfactant treatment is variable, but there is usually a rapid improvement in oxygenation and a reduction in requirements for ventilatory support. Concurrent improvements in lung mechanics have been demonstrated in animals $^{1-4}$ but most studies in ventilated human infants have not shown consistent early changes in lung mechanics after exogenous surfactant. $^{5-11}$ This inconsistency may reflect differences both in methods of measuring lung mechanics in infants and between various surfactants. Changes in dynamic compliance after surfactant treatment are more susceptible to distortion by ventilator management than changes in static compliance measured concurrently in the same infants. ${ }^{12}$ Naturally derived surfactants appear to have a more rapid clinical effect than synthetic ones. ${ }^{4}$ We report changes in lung mechanics in infants treated with natural and synthetic surfactant, using a single breath passive expiratory flow technique to measure the static compliance of the respiratory system (Crs).

\section{Patients and methods}

SURFACTANT TREATMENT

Newborn infants admitted to the teaching hospitals in Dundee and Edinburgh were studied between August 1991 and August 1992 as part of a randomised controlled trial to test the hypothesis that regular information about respiratory mechanics improves clinical outcome in mechanically ventilated neonates.

Infants from both centres were treated with surfactant if between 2 and 72 hours of age they required mechanical ventilation for respiratory distress syndrome and had an arterial/alveolar oxygen $(\mathrm{a} / \mathrm{A})$ ratio $<0 \cdot 22$. Between August 1991 and December 1991 infants were treated with Curosurf (Chiesi Farmaceutici) according to the protocol of Curosurf $4,{ }^{13}$ a trial of alternative dose regimens. From January 1992 to August 1992 infants received Exosurf Neonatal (Wellcome).

Curosurf is a preparation of polar lipids, isolated from minced pigs lungs. It contains approximately 99\% lipids, mainly phospholipids, and $1 \%$ low molecular weight hydrophobic apoproteins SP-B and SP-C. ${ }^{14}$ Infants were randomly assigned to receive either 1.25 or $2.5 \mathrm{ml} / \mathrm{kg}$ body weight $(100 \mathrm{mg}$ or $200 \mathrm{mg} / \mathrm{kg}$ ) with the aim of achieving rapid distribution throughout the lung. Half was delivered into each main bronchus by positioning the infant on one side before instilling the surfactant intratracheally and continuing mechanical ventilation in that position for one minute. The procedure was then repeated on the opposite side. Exosurf is a synthetic surfactant which contains $13.5 \mathrm{mg} / \mathrm{ml}$ of dipalmitoyl phosphatidyl choline, $1.5 \mathrm{mg} / \mathrm{ml}$ cetyl alcohol, $1 \mathrm{mg} / \mathrm{ml}$ tyloxapol in $0 \cdot 1 \mathrm{~N}$ sodium chloride and no surfactant apoproteins. ${ }^{2}$ Over approximately $20-30$ minutes $5 \mathrm{ml} / \mathrm{kg}$ was administered into the proximal endotracheal tube. The infants remained supine and mechanical ventilation continued throughout. Exosurf was 
administered more slowly than Curosurf to reduce the risk of poorer tolerance of the larger volume.

Oxygenation, ventilator efficiency index (VEI), and static Crs were assessed in each infant shortly before and as close as possible to three and 12 hours after the first dose of surfactant. All the infants were ventilated with Sechrist IV $100 \mathrm{~b}$ pressure limited, time cycled, continuous flow ventilators. The investigators were not responsible for the clinical care of the infants. The study was accepted by the ethical committees of both hospitals. Written informed consent was obtained from one or both parents before including their infant in the study.

\section{STATIC CRS MEASUREMENTS}

Static Crs was measured using a computerised passive expiratory flow technique as previously described, ${ }^{15}$ using software developed at the Children's Hospital, Toronto by Professor A C Bryan, Dr M H Bryan, and Dr P N Le Souef. To standardise for body size, Crs values were corrected for body length because we had found this slightly more accurate than correction for weight in predicting both hospital death and an immature lung phospholipid profile. ${ }^{1516}$ All Crs results were calculated as the mean of 3-6 satisfactory breaths. Breaths were only accepted if there was a clearly defined pressure plateau (approximately 200 $\mathrm{msec}$ ) after airway occlusion, if the linear portion of the expiratory flow-volume curve accounted for two thirds or more of the expiration, and if the correlation coefficient for the slope of the asymptote to the flow-volume curve was $>0.996$. Studies were only accepted if they had a within-study coefficient of variation between breaths of $<15 \%$ and no study required exclusion on this criterion. In comparing sequential studies on the same infant we planned to conduct them all within a range of expired volume of $5-10 \mathrm{ml} / \mathrm{kg}$ body weight. Occasionally the expired volume was less than this in infants with very stiff lungs. None of these results was excluded, as subsequent studies in these infants were conducted at similar pressures or expired volumes. Changes in Crs were expressed as percentage differences of the pretreatment value. We planned before analysis to subdivide the infants according to whether or not their static Crs before treatment was consistent with surfactant deficiency $\left(<1.8 \mathrm{ml} / \mathrm{cm} \mathrm{H}_{2} \mathrm{O} / \mathrm{m}\right) .{ }^{16}$

\section{OXYGENATION}

Arterial oxygen tension $\left(\mathrm{PaO}_{2}\right)$ was measured intermittently by blood gas analysis. Oxygenation was expressed as the fractional inspired oxygen $\left(\mathrm{FiO}_{2}\right)$ required at the time of study to maintain the infants' arterial or continuously monitored transcutaneous oxygen tension between 6 and $10.3 \mathrm{kPa}$ or their oxygen saturation between 90 and $94 \%$ by continuous pulse oximetry. Transcutaneous oxygen tension was calibrated against $\mathrm{PaO}_{2}$ by intermittent arterial puncture.
VENTILATOR REQUIREMENTS

In order to adjust for variations in ventilator settings between infants, we used the VEI devised by Notter et al. ${ }^{17}$ This index estimates alveolar ventilation in relation to ventilator settings and can be calculated by the equation:

$$
\mathrm{VEI}=\frac{3800}{\mathrm{p} \times \mathrm{f} \times \mathrm{PaCO}_{2}}
$$

where $\mathrm{p}$ is the inspiratory pressure minus the expiratory pressure of the ventilator, $f$ is the ventilator rate in cycles per minute, and $\mathrm{PaCO}_{2}$ is the arterial carbon dioxide tension in $\mathrm{mm}$ $\mathrm{Hg}$. VEI increases rapidly as ventilation requirements become minimal. Therefore all VEI values of $>1$ were defined as 1 in the group comparisons.

\section{STATISTICAL ANALYSIS}

Results were analysed using SPSS-PC and Minitab. Variables were compared three and 12 hours after treatment with their corresponding pretreatment value in paired group analyses using the Wilcoxon matched pairs signed ranks test. Distributions of each variable were compared using the MannWhitney U test. A two tailed probability was accepted as statistically significant if $\mathrm{p}<0.05$.

\section{Results}

During the study period 111 infants were treated with surfactant in the two centres. Of these the 88 who were enrolled in this study (table 1) did not differ significantly in important prognostic characteristics. Pairs of Crs measurements were made successfully in 73 of these 88 infants $(83 \%)$. The reasons for failure to obtain Crs data in the others were (i) inability to obtain adequate pressure plateaux after airway occlusion (either because of air leaks around the endotracheal tube or failure to induce a Hering-Breuer reflex in active infants) or (ii) alinearity of the flow-volume relationship. Of the 15 infants without successful Crs measurements nine received Curosurf and six Exosurf. There were no statistically significant differences between them and the babies in whom Crs was measured successfully in birth weight, gestational age, or oxygen requirement before

Table 1 Infants eligible for study, enrolled and successfully measured. Gender, gestation, birth weight, and length by surfactant; data are expressed as median (range)

\begin{tabular}{lcc} 
& Curosurf & Exosurf \\
\hline Eligible & 56 & 55 \\
M/F & $35 / 21$ & $33 / 22$ \\
Gestation (weeks) & $29(23-37)$ & $30(23-38)$ \\
Birth weight (g) & $1253(580-3250)$ & $1370(600-4150)$ \\
Enrolled & 48 & 40 \\
M/F & $31 / 17$ & $26 / 14$ \\
Gestation (weeks) & $29(23-35)$ & $29(25-38)$ \\
Birth weight (g) & $1226(580-2540)$ & $1285(607-4150)$ \\
Measured & 39 & 34 \\
M/F & $26 / 13$ & $21 / 13$ \\
Gestation (weeks) & $29(25-35)$ & $29(25-38)$ \\
Birth weight (g) & $1253(677-2540)$ & $1285(607-4150)$ \\
Length (cm) & $38(32-49)$ & $40(33-52)$ \\
\hline
\end{tabular}


Table 2 Pretreatment patient characteristics by surfactant and initial Crs; data are expressed as median (range)

\begin{tabular}{|c|c|c|c|c|c|c|}
\hline & $\begin{array}{l}\text { Curosurf } \\
\left(<1 \cdot 8 \mathrm{mU} / \mathrm{cm} \mathrm{H} \mathrm{H}_{2} \mathrm{O} / \mathrm{m}\right) \\
(n=32)\end{array}$ & $\begin{array}{l}\text { Exosurf } \\
\left(<1 \cdot 8 \mathrm{~mL} / \mathrm{cm} \mathrm{H}_{2} \mathrm{O} / \mathrm{m}\right) \\
(n=26)\end{array}$ & $\begin{array}{l}\text { Curosurf } \\
\left(\geqslant 1 \cdot 8 \mathrm{~mL} / \mathrm{cm} \mathrm{H}_{2} \mathrm{O} / \mathrm{m}\right) \\
(n=7)\end{array}$ & $\begin{array}{l}\text { Exosurf } \\
\left(\geqslant 1 \cdot 8 \mathrm{~mL} / \mathrm{cm} \mathrm{H} \mathrm{H}_{2} \mathrm{O} / \mathrm{m}\right) \\
(n=8)\end{array}$ & $\left.\underset{\substack{(<1 \\
(n=58)}}{A l l} \mathrm{~mL} \mathrm{~cm} \mathrm{H} \mathrm{H}_{2} \mathrm{O} / \mathrm{m}\right)$ & $\begin{array}{l}\text { All } \\
\left(\geqslant 1.8 \mathrm{ml} / \mathrm{cm} \mathrm{H}_{2} \mathrm{O} / \mathrm{m}\right) \\
(n=15)\end{array}$ \\
\hline $\begin{array}{l}\text { Gestation } \\
\text { Birth weight (g) } \\
\text { Length (cm) } \\
\text { M/F } \\
\text { Age at first dose }\end{array}$ & $\begin{array}{c}28(25-35) \\
1159(677-2540) \\
37(32-47) \\
22 / 10\end{array}$ & $\begin{array}{c}29(25-38) \\
1240(607-4150) \\
39(33-52) \\
15 / 11\end{array}$ & $\begin{array}{c}32(28-35) \\
1690(1263-2460) \\
44(37-49) \\
4 / 3\end{array}$ & $\begin{array}{l}\text { 7) } \\
-3600) \\
1)\end{array}$ & $\begin{array}{c}28(25- \\
1195(607 \\
38(32- \\
37 / 21\end{array}$ & $\begin{array}{c}32(25-37) \dagger \\
2260(703-3600) \ddagger \\
46(34-51) \ddagger \\
10 / 5\end{array}$ \\
\hline $\begin{array}{l}\text { (decimal hour) } \\
\text { Initial Crs/m } \\
\text { Initial FIO } \\
\text { Initial VEI }\end{array}$ & $\begin{array}{l}5.00(2.35-37.2) \\
1.1(0.6-1.6) \\
0.68(0.32-1.0) \\
0.13(0.05-0.43)^{\star}\end{array}$ & $\begin{array}{l}5 \cdot 10(3 \cdot 15-50 \cdot 8) \\
1 \cdot 1(0 \cdot 5-1 \cdot 7) \\
0.73(0 \cdot 30-0.95) \\
0.12(0.08-0.26)^{\star}\end{array}$ & $\begin{array}{l}16.98(3.63-53.5) \\
2 \cdot 1(1.8-2 \cdot 6) \\
0 \cdot 60(0 \cdot 50-1.0) \\
0.19(0.11-0.64)\end{array}$ & $\begin{array}{c}22 \cdot 65(5 \cdot 13-41 \cdot 32) \\
2 \cdot 1(1 \cdot 8-2 \cdot 7) \\
0 \cdot 63(0 \cdot 48-0 \cdot 90) \\
0 \cdot 16(0 \cdot 09-1 \cdot 0)\end{array}$ & $\begin{array}{l}5 \cdot 01(2 \cdot 35-50 \cdot 8) \dagger \\
1 \cdot 1(0 \cdot 5-1 \cdot 7) \\
0 \cdot 70(0 \cdot 30-1 \cdot 0) \\
0 \cdot 13(0.05-0 \cdot 43)^{\star}\end{array}$ & $\begin{array}{l}16.98(3.63-53.5) \dagger \\
2 \cdot 1(1 \cdot 8-2 \cdot 7) \\
0 \cdot 60(0 \cdot 48-1 \cdot 0) \\
0 \cdot 19(0.09-1 \cdot 0)^{\star}\end{array}$ \\
\hline
\end{tabular}

Symbols denote significant difference between groups (Mann-Whitney $U$ ).

${ }^{\star} \mathrm{p}=<0.05, \mathrm{p}=<0.005, \neq \mathrm{p}=<0.0005$.

treatment or in changes in oxygen requirements and VEI after treatment with either surfactant.

The mean (SD) within study coefficient of variation in Crs between accepted breaths in 134 sequentially analysed studies was 6.7 (3.5)\%. The mean (SD) difference between the results of paired studies performed five minutes apart by the same observer on 15 infants $>12$ hours after treatment with surfactant was $0.2(10.5) \%$. The mean (SD) difference between the results obtained by two different observers analysing the same data,
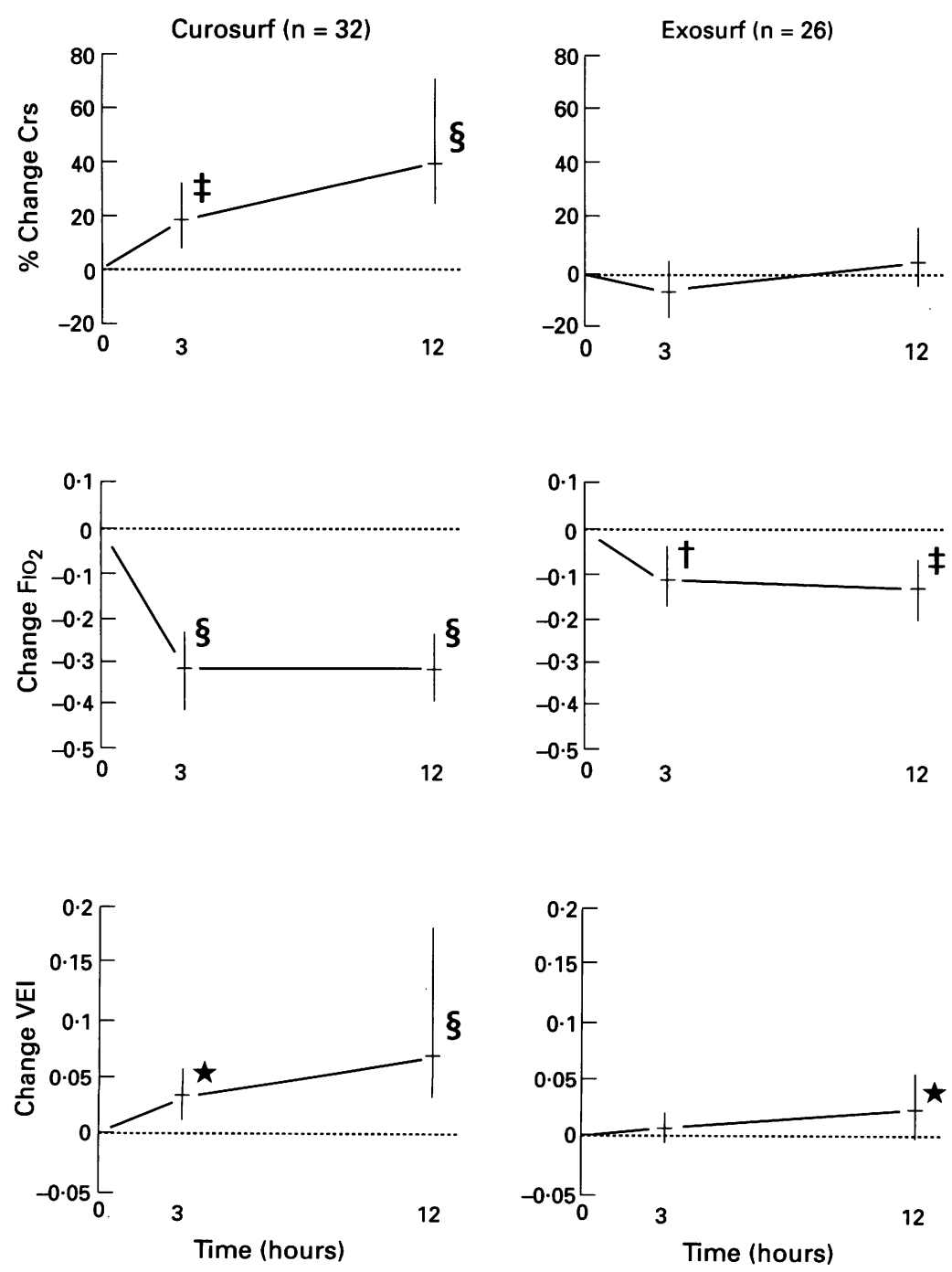

Figure 1 Changes after surfactant administration in infants with initial Crs $<1.8 \mathrm{~mL} / \mathrm{cm}$ $\mathrm{H}_{2} \mathrm{O} / \mathrm{m}$. Graphs show medians with $95 \%$ confidence intervals. Symbols denote significant difference from value before treatment: ${ }^{\star} p<0.05, \dagger p<0.01, \ddagger p<0.005, \$ p=0.0001$ by Wilcoxon signed rank test. blind to the results obtained by the other in 71 randomly selected studies was $0 \cdot 4(7 \cdot 4) \%$.

Of the 73 infants with valid Crs data, there were no differences in the distributions of birth weight, length, gestational age, oxygen requirement, age at treatment, and static Crs before treatment between those treated with Curosurf and those treated with Exosurf (table 2). The infants with initial values of static Crs suggesting surfactant deficiency $\left(<1.8 \mathrm{ml} / \mathrm{cm} \mathrm{H}_{2} \mathrm{O} / \mathrm{m}\right)$ who received Exosurf had slightly greater ventilation requirements (VEI) before treatment than those treated with Curosurf. There were 15 infants whose static Crs before treatment was not consistent with surfactant deficiency $\left(\geqslant 1.8 \mathrm{ml} / \mathrm{cm} \mathrm{H}_{2} \mathrm{O} / \mathrm{m}\right)$. They were significantly heavier, longer, easier to ventilate, older at time of treatment, and of later gestation than those whose initial Crs was consistent with surfactant deficiency.

The changes in Crs, oxygen requirements, and VEI seen after treatment are shown in figs 1 and 2. Of the 58 infants with initial Crs $<1.8 \mathrm{ml} / \mathrm{cm} \mathrm{H}_{2} \mathrm{O} / \mathrm{m}$ (fig 1) those treated with Curosurf showed a median improvement in Crs of $18 \%(p=0.002)$ three hours after treatment increasing to $39 \%(p=0.0001)$ at 12 hours. These changes were accompanied by significant improvements in oxygenation and VEI at both three and 12 hours. The infants treated with Exosurf showed no statistically significant changes in $\mathrm{Crs}$ at three or 12 hours, with median changes of $-6 \cdot 2 \%$ $(p=0.24)$ at three hours and $+5 \%(p=0.28)$ at 12 hours. Their oxygen requirements were significantly lower at three hours than before treatment but the VEI did not improve until 12 hours. The median reduction in oxygen requirement was greater after Curosurf than Exosurf both at three hours (change in $\mathrm{FIO}_{2}$ -0.32 compared with $-0.11 ; p<0.001)$ and at 12 hours (change in $\mathrm{FIO}_{2}-0.32$ compared with $-0.13 ; \mathrm{p}<0.005)$ after treatment. If the Crs results for these infants are expressed in absolute terms rather than as percentage changes, the same pattern is observed with median pretreatment Crs for the Curosurf treated infants of $1 \cdot 1 \mathrm{ml} / \mathrm{cm} \mathrm{H}_{2} \mathrm{O} / \mathrm{m}$ and median change at three hours $+0 \cdot 2$ $(p=0.0037)$, and median pretreatment Crs for the Exosurf treated infants $1.1 \mathrm{ml} / \mathrm{cm}$ $\mathrm{H}_{2} \mathrm{O} / \mathrm{m}$ and median change at three hours $-0 \cdot 1(p=0 \cdot 156)$. At each time point in fig 1 the medians and $95 \%$ confidence intervals for each of the three variables were calculated from the same infants except that there was 

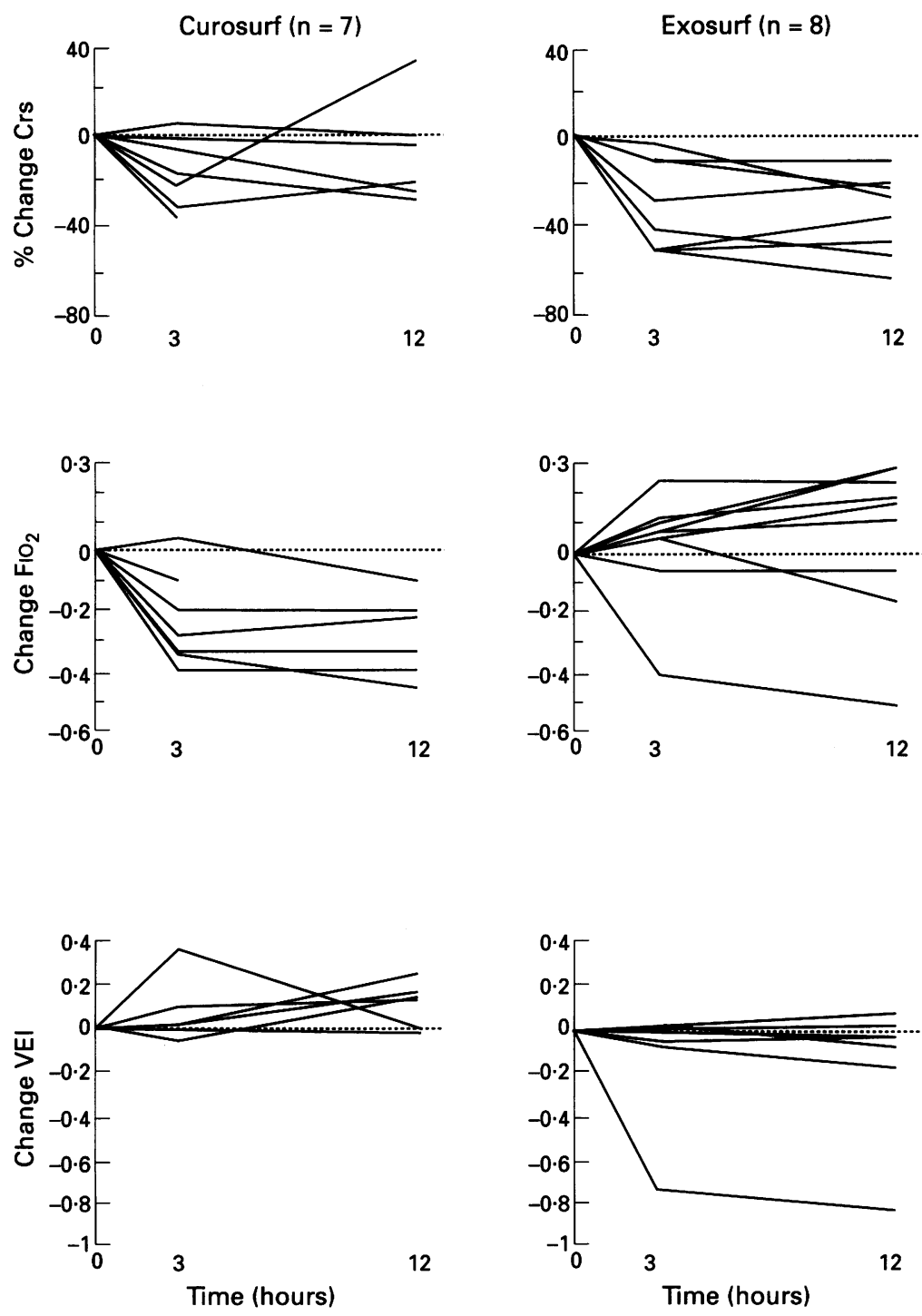

Figure 2 Changes after surfactant administration in infants with initial Crs $\geqslant 1.8 \mathrm{~mL} / \mathrm{cm}$ $\mathrm{H}_{2} \mathrm{O} / \mathrm{m}$. Lines represent individual infants.

one missing data point for the VEI in an infant treated with Exosurf.

Of the 15 infants with initial $\mathrm{Crs} \geqslant 1.8$ $\mathrm{ml} / \mathrm{cm} \mathrm{H}_{2} \mathrm{O} / \mathrm{m}$ (fig 2), all eight treated with Exosurf and five out of seven treated with Curosurf showed a fall in Crs after treatment. The infants treated with Curosurf showed an overall reduction in their oxygen requirements while those treated with Exosurf did not. There was no consistent pattern to the changes in the VEI.

\section{Discussion}

In this study infants diagnosed as respiratory distress syndrome with a/A ratio $<0.22$ showed rapid improvements in static Crs, oxygenation, and ventilation requirements after porcine surfactant if their initial static Crs was consistent with surfactant deficiency. A similar group of infants showed no improvement in static compliance, a smaller improvement in oxygenation, and no significant reduction in ventilation requirements over the same time after synthetic surfactant. It should be stressed that these two groups were not randomly assigned to natural or synthetic surfactant, so this comparison should be interpreted with caution.
However, the results are consistent with individual studies of naturally derived ${ }^{12}$ and synthetic surfactants ${ }^{11}$ using the same methods in human infants and with randomised studies in animals. ${ }^{4}$ Improved pulmonary pressurevolume characteristics are therefore likely to be an important factor in the rapid clinical improvements seen after natural surfactant.

Several clinical studies on ventilated human infants have failed to show rapid improvements in lung mechanics that would explain the immediate improvements in gas exchange seen after surfactant treatment. ${ }^{5-11}$ Some of these studies involved infants treated with synthetic surfactant,, 5611 which may have slower effects on lung mechanics than natural surfactant. Three considered infants treated with natural surfactants, who showed rapid improvements in oxygenation but no concurrent improvements in dynamic compliance during ventilation. ${ }^{8-10}$ The improvements in gas exchange have been attributed to documented improvements in functional residual capacity (FRC). These observations and conclusions may partly reflect the limitations inherent in measuring dynamic compliance. When positive end expiratory pressure is being applied to compliant lungs, they may remain sufficiently distended at end expiration to cause the lungs to operate higher up on the flatter part of the pressure volume curve during ventilator breaths. Under these circumstances there might be no net improvement in dynamic compliance but a large improvement in FRC and hence oxygenation. The passive expiratory flow technique for measuring static compliance avoids this problem by measuring expired volume from peak inflation to zero (atmospheric) pressure. This has recently been elegantly demonstrated by Kelly et al who measured compliance by both methods in a population of infants treated with a naturally derived surfactant and demonstrated significant improvements in static compliance without improvements in dynamic compliance. ${ }^{12}$ If the lungs are operating on the flat upper portion of the pressure volume curve because of excessive peak inflation pressure, however, this would lead to underestimation of changes in both dynamic and static compliance. Indeed Kelly et al reported improvements in both static and dynamic compliance when peak inflation pressure was reduced after surfactant treatment. ${ }^{12}$

Infants in this study are unlikely to have been ventilated with excessive peak inflation pressure as their expired volumes, extrapolated to zero flow and atmospheric pressure, were $5-10 \mathrm{ml} / \mathrm{kg}$ body weight or less. Although static Crs in respiratory distress syndrome improved after treatment and oxygen requirements often decreased substantially in this study the infants still required to be ventilated, often vigorously, and their respiratory compliance did not reach the levels seen in infants without lung disease. Surfactant therefore alleviated but did not cure their respiratory distress syndrome. ${ }^{12}$

Part of the difference in the speed of response that we observed between the two surfactants in our study may reflect differences 


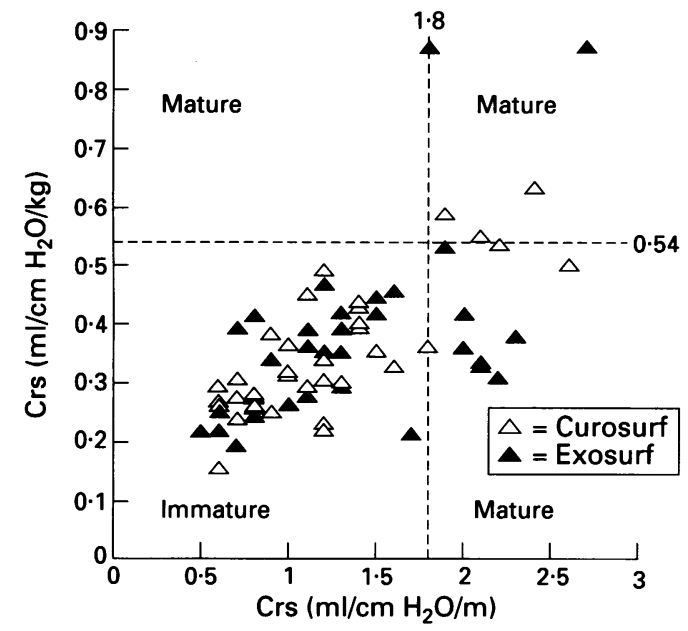

Figure 3 Crs corrected to weight $(\mathrm{kg})$ in relation to $\mathrm{Crs}$ corrected to length $(\mathrm{m})$.

in the methods of surfactant administration. Nevertheless, rapid response to a surfactant may not lead to improvements in adverse clinical outcome. In the Curosurf 4 trial for example, oxygenation and ventilation requirements improved faster in infants given an initial dose of $200 \mathrm{mg} / \mathrm{kg}$ of surfactant than in those given $100 \mathrm{mg} / \mathrm{kg}$ but there was no clear difference in mortality or major morbidity between them. ${ }^{13}$

The observations that in $15 / 73(21 \%)$ of the infants static Crs was consistent with mature lungs $\left(\geqslant 1.8 \mathrm{ml} / \mathrm{cm} \mathrm{H}_{2} \mathrm{O} / \mathrm{m}^{16}\right)$ before surfactant treatment and that in 13 of them static Crs fell after treatment raise important questions. Should they have received surfactant? Did it do more harm than good? Are clinicians being tempted to overdiagnose respiratory distress syndrome now that an effective treatment is available? ${ }^{18-20}$ These 15 infants may have had respiratory problems other than respiratory distress syndrome, which can be difficult to discriminate on an early chest radiograph. If so, the apparently poorer lung mechanics and gas exchange of the eight 'mature' infants after Exosurf may have reflected the adverse effects of the greater volume of fluid instilled into their lungs. The seven mature infants treated with Curosurf still showed a reduction in their oxygen requirements, which might reflect more rapid clearance of administered fluid and continuing improvement in their underlying condition. Larger numbers are required to validate these observations.

Should static Crs be corrected for length or for weight? The lack of improvement in static Crs after surfactant treatment in 13 infants classified as mature (with static Crs $\geqslant 1.8$ $\mathrm{ml} / \mathrm{cm} \mathrm{H}_{2} \mathrm{O} / \mathrm{m}$ ) seems consistent with the behaviour of mature lungs. However, had we instead corrected static Crs for weight using a predefined cut off for lung maturity of $\geqslant 0.54$ $\mathrm{ml} / \mathrm{cm} \mathrm{H}_{2} \mathrm{O} / \mathrm{kg}$ based on previous work, ${ }^{16}$ only five infants would have been identified as having mature lungs (fig 3). Furthermore, six out of the eight infants treated with Exosurf whose lung mechanics and gas exchange did not improve would have been identified as immature, which seems inconsistent with their lack of response to surfactant.
This supports the suggestion that correction of static Crs for weight may slightly overestimate the disease severity of larger infants relative to smaller ones. ${ }^{15}$ In this and two other studies therefore, ${ }^{15} 16$ correction of static Crs for length appears to have been more informative than correction for weight. This may be important in planning future studies. Nevertheless until reliable data from randomised trials are available, we would urge caution in giving or withholding surfactant on the basis of a single lung function test.

In summary, this study describes early responses to treatment with two surfactants. The results do not provide definitive evidence in favour of either. There may be moderate but important differences in major clinical outcomes between natural and synthetic surfactants, but to demonstrate them reliably would require international collaboration. For example, a sample of 4000 would be needed to detect a reduction in the risk of death or bronchopulmonary dysplasia in high risk infants from $67 \%$ to $62 \%$ with $90 \%$ power at $2 \mathrm{p}=0 \cdot 05 .^{21}$ Respiratory distress syndrome remains a common and disabling condition. Detecting differences of this magnitude is logical and feasible ${ }^{18}$ and poses a worthwhile challenge to the international community.

We thank the nursing and medical staff in the neonatal units at Simpson Memorial Maternity Hospital and Ninewells Hospital for their support and Professors Richard Olver and Neil McIntosh for their encouragement. This work was supported by grants from the Wellcome Trust, Scottish Office Home and Health Department, Action Research, and Scottish Chest Heart and Stroke Association. Curosurf was the gift of Chies analysed independently of the company. A video of the static Crs technique is available from WOT-M at cost price.

1 Noack G, Curstedt T, Grossman G, Nilsson R, Robertson B. Passive expiratory flow-volume recordings in immature newborn rabbits. Effect of surfactant replacement on the time constant of the respiratory system. Respiration 1990; 57: $1-5$.

2 Tooley WH, Clements JA, Muramatsu K, Brown CL, Schlueter MA. Lung function in prematurely delivered rabbits treated with a synthetic surfactant. Am Rev Respir Dis 1987; 136: 651-6.

3 Vidyasagar D, Maeta H, Raju T, et al. Bovine surfactant (Surfactant TA) therapy in immature baboons with hyaline membrane disease. Pediatrics 1985; 75: 1132-42.

4 Cummings J, Holm BA, Hudak ML, Hudak BB, Ferguson WH, Egan EA. A controlled comparison of four different surfactant preparations in surfactant-deficient preterm lambs. Am Rev Respir Dis 1992; 145: 999-1004.

5 Milner AD, Vyas H, Hopkin IE. Effect of exogenous surfactant on total respiratory system compliance. Arch Dis Child 1984; 59: 369-71.

6 Morley CJ, Greenough A. Respiratory compliance in premature babies treated with artificial surfactant (ALEC). Arch Dis Child 1991; 66: 467-71.

7 Bhutani VK, Abassi S, Long WA, Gerdes JS. Pulmonary mechanics and energetics in preterm infants who had respiratory distress syndrome treated with synthetic surfactant. F Pediatr 1992; 120: S18-24.

8 Bhat R, Dziedzic K, Bhutani VK, Vidyasagar D. Effect of single dose surfactant on pulmonary function. Crit Care Med 1990; 18: 590-4.

9 Davis J, Veness-Meehan K, Notter R, Bhutani V, Kendig $\mathrm{J}$, Shapiro $\mathrm{D}$. Changes in pulmonary mechanics after the administration of surfactant to infants with respiratory distress syndrome. $N$ Engl $f$ Med 1988; 319: 476-9.

10 Goldsmith L, Greenspan J, Rubenstein D, Wolfson M, Shaffer $T$. Immediate improvement in lung volume after exogenous surfactant: alveolar recruitment versus increased distension. F Pediatr 1991; 119: 424-8.

11 Pfenninger J, Aebi C, Bachmann D, Wagner BP. Lung mechanics and gas exchange in ventilated preterm infants during treatment of hyaline membrane disease with multiple doses of artificial surfactant (Exosurf). Pediatr Pulmonol 1992; 14: 10-5.

12 Kelly E, Bryan H, Possmayer F, Frndova H, Bryan C. Compliance of the respiratory system in newborn infants pre- and postsurfactant replacement therapy. Pediatr Pulmonol 1993; 15: 225-30.

13 Halliday HC, Tarnow-Mordi W, Corcoran JD, Patterson CC. Multicentre randomised trial comparing high and 
low dose surfactant regimens for the treatment of respiratory distress syndrome (the Curosurf 4 trial). Arch Dis Child 1993; 69: 276-80.

14 Robertson B, Curstedt $\mathrm{T}$, Johannson J, Jornvall $\mathrm{H}$, Kobayshi $T$. Structural and functional characterisation of porcine surfactant isolated by liquid-gel chromatography. In: von Wichert P, Muller B, eds. Basic research on hy. In: von Wichert $\mathrm{P}$, Muller B, eds. Basic research on lung surfactant. Progress in respiration research

Switzerland: Karger, 1989; 25: 237-46.

15 Tarnow-Mordi WO, Wilkie RA, Reid E. Static respiratory compliance in the newborn. I: A clinical and prognostic index for mechanically ventilated infants. Arch Dis Child 1994; 70: F11-5.

16 Wilkie RA, Bryan MH, Tarnow-Mordi WO. Static respiratory compliance in the newborn. II: Its potential for improving the selection of infants for early surfactant treatment. Arch Dis Child 1994; 70: F16-8.
17 Notter RH, Egan EA, Kwong MS, Holm BA, Shapiro DL. Lung surfactant replacement in premature lambs with extracted lipids from bovine lung lavage: effects of dose, dispersion technique and gestational age. Pediatr Res 1985; 19: 569-77.

18 OSIRIS Collaborative Group Early versus delayed neonatal administration of a synthetic surfactant - the judgement of OSIRIS. Lancet 1992; 340: 1363-9.

19 Annibale DJ, Hulsey TC, Wallin LA, Engstrom PC. Clinical diagnosis and management of respiratory distress in preterm neonates: effect of participation in a controlled trial. Pediatrics 1992; 90: 397-400.

20 Tarnow-Mordi WO. The OSIRIS trial. Lancet 1993; 341: 174.

21 Horbar JD, Wright LL, Soll RP, et al. A multicenter randomised trial comparing two surfactants. Pediatr Res 1993; 4: 215A (abstract 1274). 